\title{
DO UTOPIAN CITY DESIGNS FROM THE SOCIAL REFORM LITERATURE OF THE SEVENTEENTH AND NINETEENTH CENTURIES RESONATE WITH A MODERN AUDIENCE?
}

\author{
Tessa MORRISONa, Mark RUBIN ${ }^{b}$ \\ ${ }^{a}$ The School of Architecture and Built Environment, The University of Newcastle, University Drive, \\ Callaghan, 2308 Australia

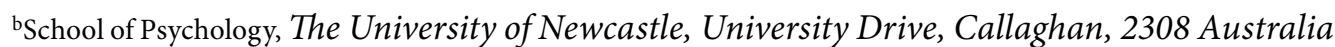 \\ E-mails: ${ }^{a}$ tessa.morrison@newcastle.edu.au (corresponding author); \\ ${ }^{b}$ mark.rubin@newcastle.edu.au
}

Received 01 November 2015; accepted 03 February 2016

\begin{abstract}
Utopian cities from social reform literature from the seventeenth and nineteenth centuries were a serious attempt to improve living and working conditions of their time. Some of this literature included a design for a city that would be complimentary to and enhance the political philosophy of the respective authors. Four of the most famous works which include a plan of a city are, Tommaso Campanella's Civitas Solis (City of the Sun) (1602), Johann Valentin Andreae's Christianopolis (1619), Robert Owen's Villages of Co-operation (1817 \& 1830) and James Silk Buckingham's Victoria (1849). These works are frequently featured in literature on utopian cities. However, no consideration is given to whether these 'utopian' cities have any value as urban plans or whether they incorporate any desirable urban features. These urban designs of the city are significant to political philosophies because the cities are presented as being integral to such philosophies. This paper considers the following questions: 'Do the main principles behind the initial political philosophies and their coinciding plan endure within the design of these cities?' 'Does a modern audience perceive in these cities the features that made them utopian in the centuries in which they were planned?'
\end{abstract}

Keywords: utopia, urban design, social reform, design history, community, seventeenth century, nineteenth century.

\section{Introduction}

The idea of the perfect city has a long history. The earliest surviving description of an ideal city was in Plato's Republic where Plato described a polis to be an imitation - a city that was ruled by philosopherkings (see Plato 1955). He did not describe the actual physical city in the Republic, only the political framework. However, amongst the final works of Plato are two dialogues between Socrates, Timaeus, Critias and Hermocrates (see Plato 1977). In the first dialogue, a complete work, Timaeus, gives an account of the world in which he lived and described the Cosmos that consisted of the four elements; air, earth, water and fire. In the second, but incomplete work, Critias, he outlined the plan of the city of Atlantis. He described the city as consisting of three concentric rings and moats. To the south of the city was a large channel that gave access to the sea while to the north was an enormous rectangular plane that was gridded by many smaller canals (Plato 1977: 136-42). In Critias, Plato also described Athens, which stood in stark contrast to Atlantis. Unlike Atlantis, Athens invoked no geometrical or numerological pattern. Indeed, it is the general symmetry of Atlantis that makes it appear more perfect and more defined.

Christianity used symmetry to define the holy city of New Jerusalem in Revelation. The symmetry emphasized holiness and perfection. The New Jerusalem was the Utopia that was beyond reach of human endeavour and was a city of escape where all good men could enter and were not barred by their earthly status and class in society. It was not until the sixteenth century that a more earthly ideal state was considered in literature.

In 1516, Thomas More wrote Utopia (see More 2001). The island of Utopia was isolated, impregnable and safe from the outside world. It is described as being 
crescent shaped, with a harbour whose entrance was rendered perilous due to shallows and reefs. There were 54 cities on the island, and each city was similar and divided into four equal parts. At the heart of the city, instead of a Temple or palace, there were gardens. The cities' plans were not described in sufficient detail to draw more than a crude ground plan; however, the centralised garden was unique to Thomas More's design until the nineteenth century. Utopia's citizens were assumed to have equal status in the society, and the town centres had an atmosphere of culture, relative luxury, and social responsibility. Although the details of the architecture and layout were not described, the emphasis was on the sameness of the architecture, which reflects the qualities of the Utopian's society. Within this closed society, the citizens of Utopia escaped the harsh realities of sixteenth century politics, war, and disease.

Until the end of the nineteenth century, Utopian cities were influenced by More's Utopia and Plato's Atlantis. The political philosophy and the design of the city became interlinked, particularly in the seventeenth and nineteenth centuries, and the design of the city was intended to enhance the political philosophies for which underpinned them.

\section{Social reform utopias}

The four cities that are examined in the current paper are, Andreae's Christianopolis, Campanella's Civitas Solis (City of the Sun), Owen's Villages of Co-operation and Buckingham's Victoria. These four cities were selected for this project because they are all described in the social reform literature, which attempted to address major social and political problems of their time, including the disease and religious and political conflicts that dominated the late sixteenth century and the early seventeenth century (Carsten 1985: 73-80). In the nineteenth century, it was poverty and a housing crisis that was a result of the enclosure movement and the Industrial Revolution that permeated the political discussion (see Williamson 2002; Bythell 1983).

It is clear that the influence of these four utopian cities inspired Ebenezer Howard in his designs for garden cities at the end of the nineteenth and early twentieth centuries (see Rockey 1981, 1983; Armitage 1958). They all included a body of political philosophy and plan of a city with a significant amount of architectural detail. All four works are famous 'utopian' models, but none of them were ever built. Thus, their "utopianism" has never been tested. This lead us to the following research questions: (1) Does the design of these four cities enhance the philosophy that is propagated in the associated literature and provide an urban environment that would act as a solution to the problems that they set out to solve? (2) Would there be any recognition in contemporary society of the fundamental principles that were incorporated into these designs?

To answer these questions, this paper will first briefly outline the descriptions of the cities, with images of the reconstructions of the cities that were created through the $3 \mathrm{D}$ computer modelling program ArchiCAD. This is followed by a discussion of the fundamental philosophies that instigated the design of the cities. Then, we discuss a research framework for analysing the environmental features of the cities. Finally, we outline and discuss the results of a research survey that was carried out in order to investigate contemporary responses to these urban designs of the seventeenth and nineteenth centuries.

\section{Description of the four cities}

The City of the Sun was written by Dominican monk Tommaso Campanella. He moved away from orthodoxy in his late twenties and became embroiled in a political movement that advocated the expulsion of Spain from Naples and Sicily. As a result, he was imprisoned for 27 years in Naples and, on his release, he was jailed in Rome. He was a prolific writer, and The City of the Sun was one of his earliest works written in prison in 1602. It remained in manuscript form and was not published until 1629.

The City of the Sun was circular and 2 miles in diameter. The city was divided into seven circuits that were named after the seven planets, and it had four streets that were orientated towards the points of the compass (Fig. 1). The city was built on a hill with a couple of the lower circuits on the plane, and each circuit consisted of a series of large attached houses which appeared to be one large palace. Arched galleries for promenading were on the upper floors, and below was an arched colonnade. Each of the six circuits were built in a similar manner, and in every ring there were communal kitchens, barns, and stores of utensils for eating and drinking (Campanella 1968: 153). In the centre and on top of the hill was the Temple. The Temple was built on a space of 350 paces. The bottom floor and the highest wall were decorated with pictures that were intended as an educational tool (see Fig.2).

Christianopolis was written by Johann Valentin Andreae, a Lutheran theologian and educationalist who is generally considered to be one of the most important German authors of the seventeenth century. His contributions included incorporating Italian literary techniques into German literature (Bleiler 2008: 30) and important works such as the anonymous documents Fama Fraternitatis dess loblichen orden des Rosenkreutzes (1614) and Confessio Fraternitatis R.C. (1615), which were 
the foundation documents of a secret Christian brotherhood called the Rosicrucian movement. Andreae refuted that he was the author of the documents, although he was keen to promote the main principles of the brotherhood (Dixon 1998). Andreae's Christianopolis was published in 1619 and was an attempt to promote a more concrete Christian brotherhood through a complete community housed in a fortified city. The city was built of brick in the shape of a square with a fortified Bastion on each corner. It had four sectors divided by roads orientated to the compass. It was designed for four hundred residents, and it consisted of four concentric rows of buildings and a central square with a large Temple (see Fig. 3). The fortifications were reinforced by eight massive towers and 16 smaller towers on the corners of the inner rows, and in the middle of the city there is an impregnable citadel. The first row of buildings that encompasses the city contained the storerooms and industry. Under the roof of the towers the community of that quarter meet to perform sacred and civil duties (Andreae 1999: 163-169).

The next two rows of buildings that encompassed the city contained the living quarters. The two rows of houses faced each other (Fig. 4). There was a vaulted colonnade supported by pillars and, on the second and third floor, there were balconies for walkways not only to move from house to house but also to walk across to the building on the other side of the street. All of the accommodation was built to the same design. Behind both of the rows of houses was a garden for common use, and another large tower divides the road and joins

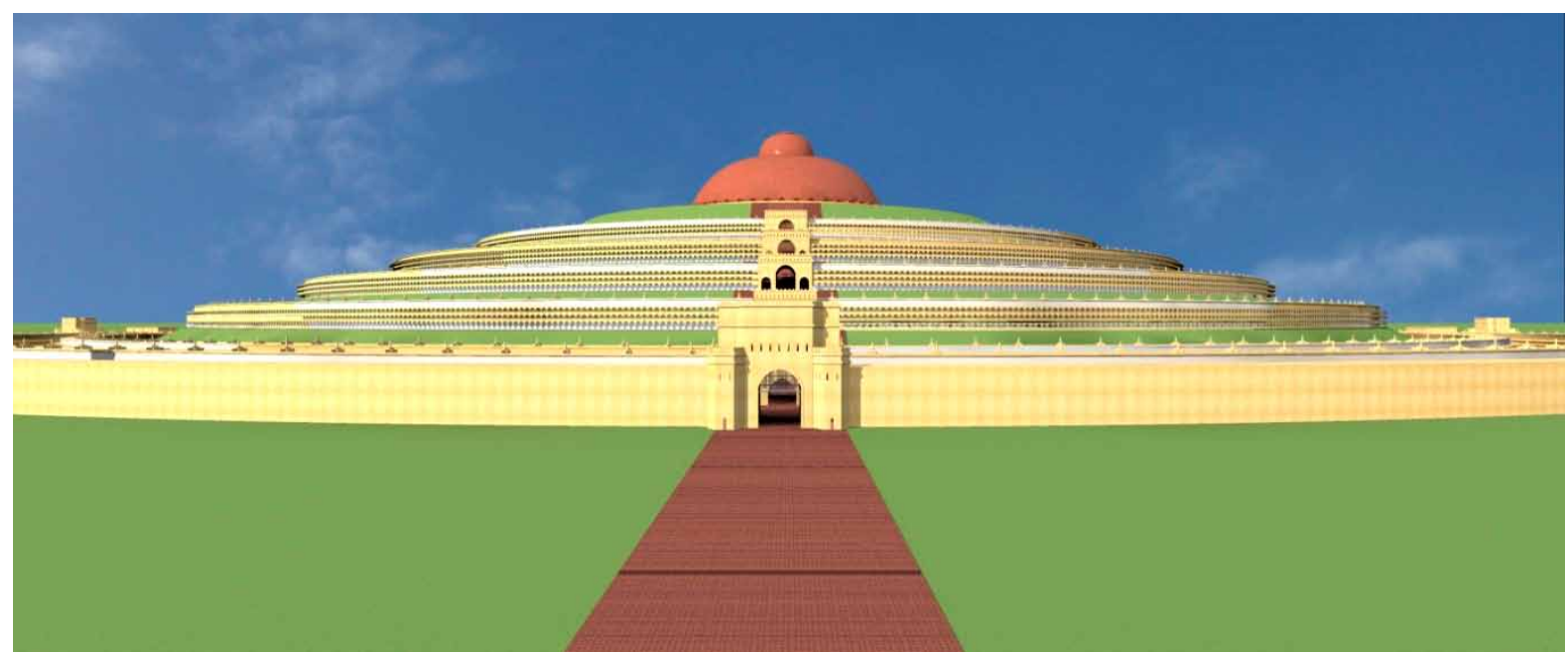

Fig. 1. Reconstruction of the City of the Sun

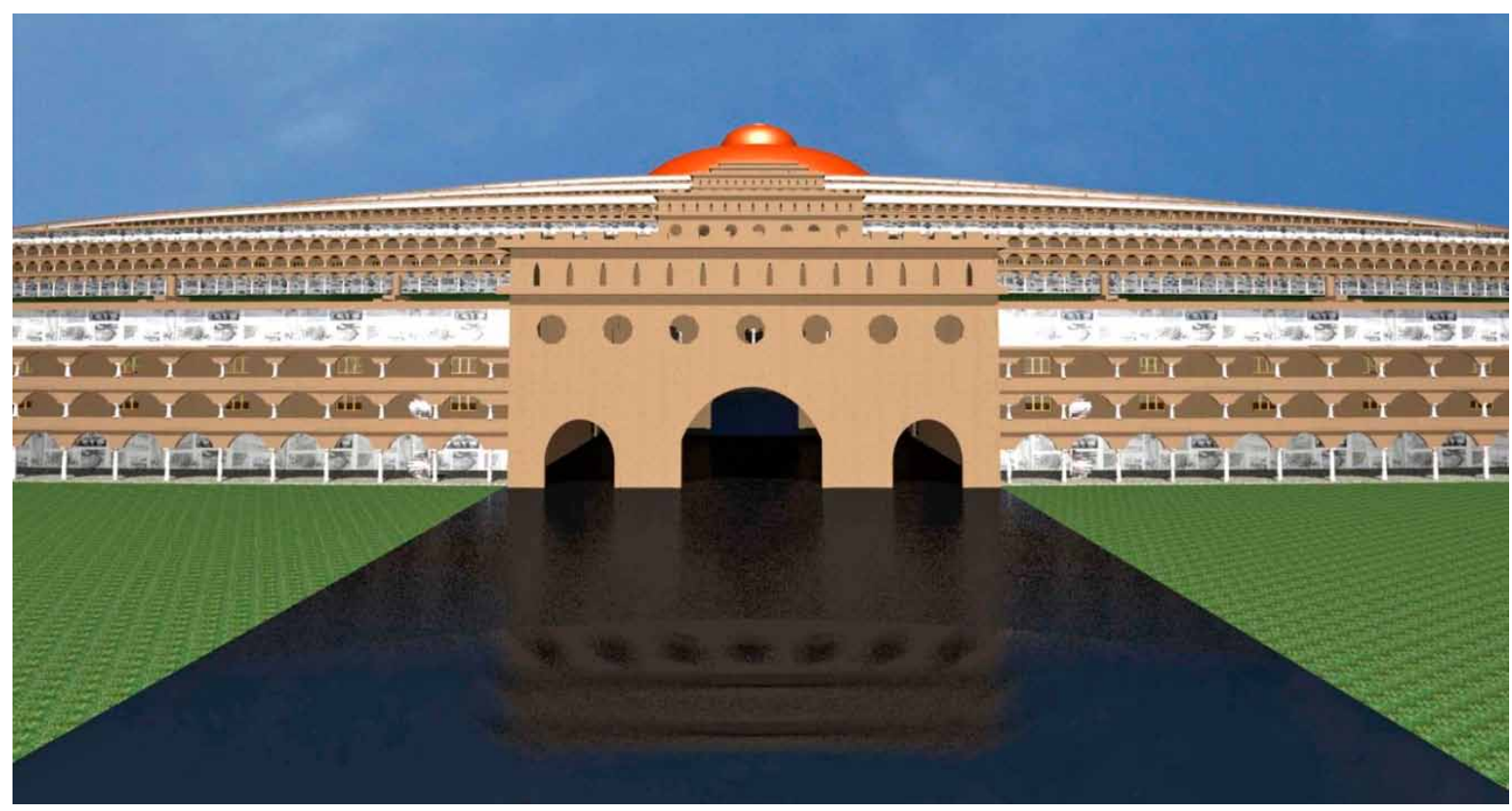

Fig. 2. Reconstruction of the City of the Sun, the first interior wall. 


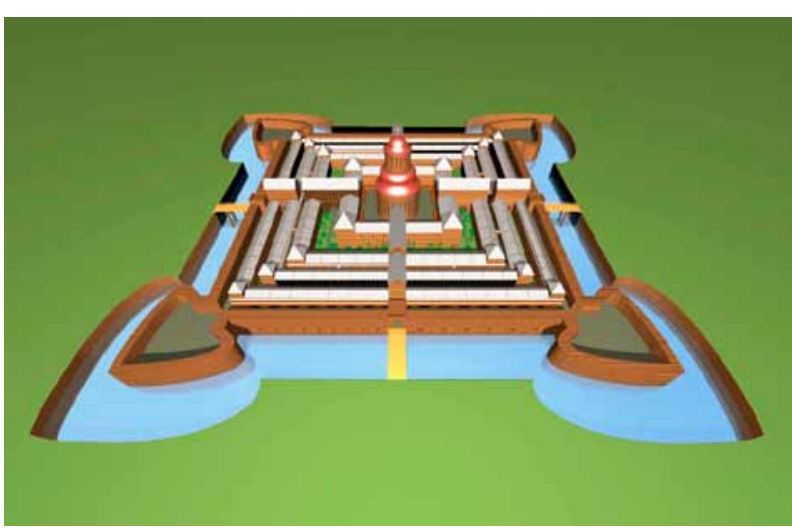

Fig. 3. Reconstruction of Christianopolis

the living quarters to the fourth row of building - the College (Andreae 1999: 170 \& 182-183). The College took up the entire fourth row. It was a dominant building, surrounded by a double row of gardens - the first from the domestic buildings, and the second a botanical Garden. Andreae called this the 'primum mobile of the community' (Andreae 1999: 186). Around the quadrangle inside the building was a cloister of 72 columns that surrounded the Temple Square. The Temple was 'a royally magnificence building in which opulence vies with art (Andreae 1999: 257).' It was 100 foot in diameter, and the body of the church was 70 feet high, and all of the four hundred citizens of the town could be accommodated within it. City of the Sun and Christianopolis were the first utopian literature published after the Thomas More's Utopia (1516) that articulated both their political philosophy and a detailed design of the city.

The third city that we considered was Robert Owen's Villages of Co-operation (1817). Robert Owen was part owner and manager of New Lanark Mills, Scotland, and is known as the Father of English Socialism. He addressed the Committee for Relief of the Manufacturing Poor in 1817 to outline his solution to the national crisis of poverty and homelessness that was a result of both the enclosure movement and the Industrial Revolution. He later published a pamphlet entitled A Report to the Committee for Relief of the Manufacturing and Industrial Poor that outlined a plan for Villages of Co-operation (see Owen 1817). In this pamphlet, he supplied a sketch of the village. This architectural plan was later revised in 1830 by Owen's architect Stedman Whitwell (1972). Whitwell's plan had similar features to Owen's original plan. It was Whitwell's complete plans of the first Village of Cooperation, New Harmony that was reconstructed for the survey (see Fig. 5). Whitwell's plan never came to fruition, and the inhabitants moved into the already

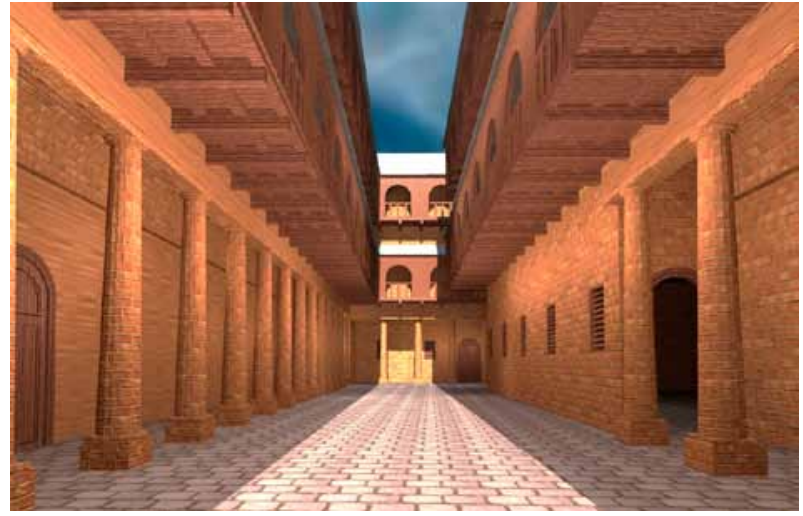

Fig. 4. Reconstruction of the rows of the domestic buildings

existing buildings and built new buildings without a consistent plan. This plan had one significant difference to the other cities that we considered: The centre of the city contained a conservatory rather than a Temple or church (see Fig. 6). There is a similarity in this to More's central gardens.

The overall plan was a square; the sides of the square were domestic apartments that were sufficient to house the ideal size of these communities, which were 1,200 inhabitants in Owen's original plan and 2,000 inhabitants in Whitwell's revised plan. In the middle of each of the rows of domestic apartments was a substantial building that served as the main entrances and the locations for the libraries, schools, reading rooms and lecture halls. Within the square were four public buildings that contained the public kitchen, dining room and everything that is required for cooking and eating, as well as the brew-houses, bake-houses, wash houses and laundries. Each one of the four public buildings had an immense tower that functioned as a chimney for the fumes of the kitchens and industry but also as an observation platform with a spiral staircase on the outside. At the corners of the complex were smaller circular buildings that housed the gymnasiums. Outside of the square were gardens that were surrounded with roads, and immediately beyond these were the buildings for mechanical and manufacturing purposes (Whitwell 1972: 6-7).

The fourth and final city that we considered was James Silk Buckingham's Victoria. In 1849, Buckingham published National Evils and Practical Remedies, with the Plan of a Model town (Buckingham 1849). This publication was presented as a solution to the ongoing national crisis in England. Buckingham was a traveller and a onetime parliamentarian for Sheffield. He was a radical reformer and was heavily influenced by Owen and the Christian Socialist movement. 


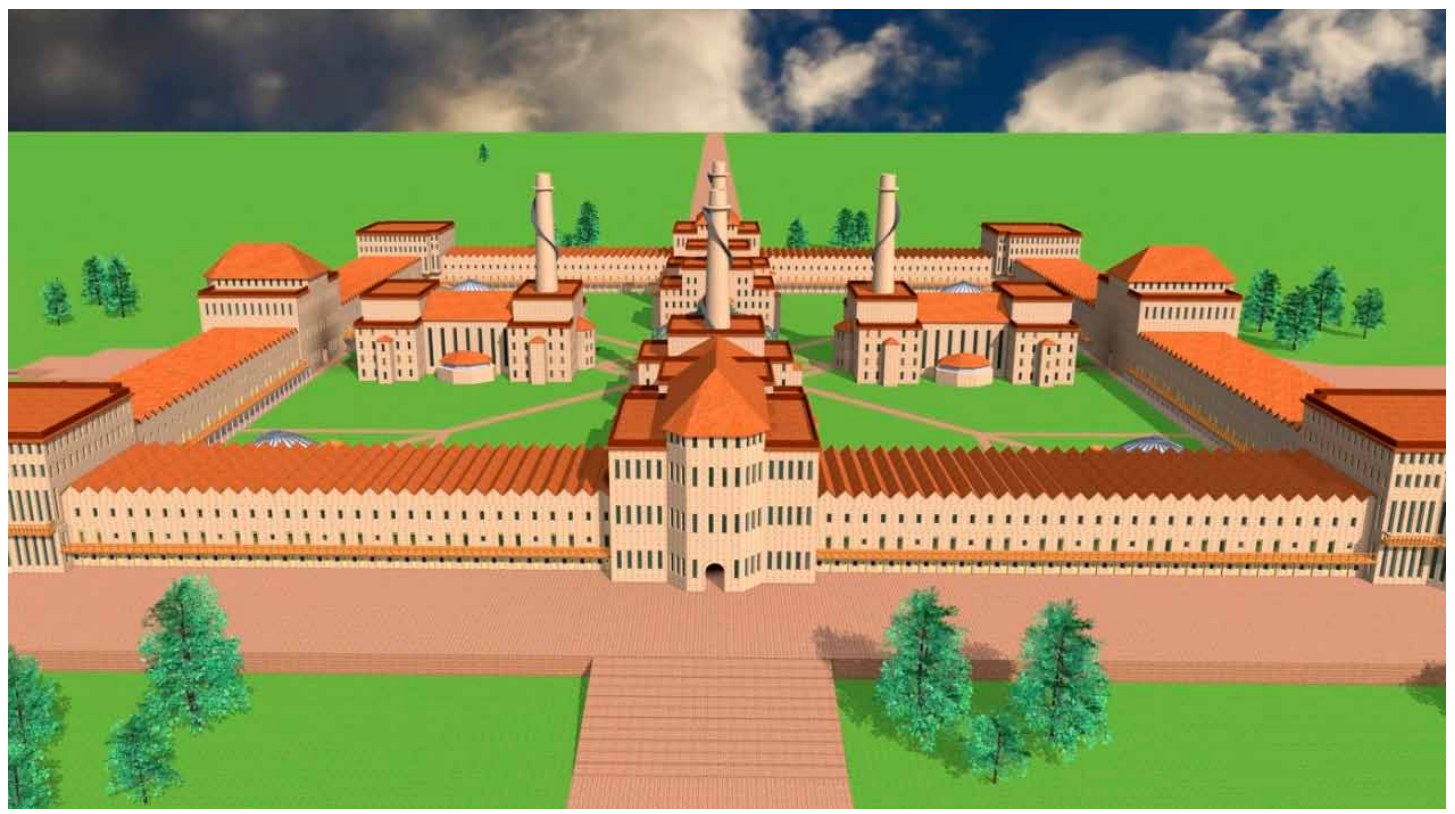

Fig. 5. Reconstruction of Whitwell's plan of the villages of co-operation

Buckingham's town, Victoria, covered a square mile and consisted of eight concentric rows. Four of these rows were domestic buildings, one row was for government offices and mansions, and the other three were arcades for the shops, workshops and winter promenades. The architecture of each of the domestic rows was different, and there was a hierarchical structure to the town and its architecture. The working class lived in the outer row, which consisted of two stories, and each side had 500 attached houses. The merchant class were located in the seventh row, which consisted of four floors with 30 attached houses per side. In between these rows were buildings for community eating, meeting areas, education and gymnasiums. In the centre was an octagonal tower that was 100 feet in diameter and crowned by a spire

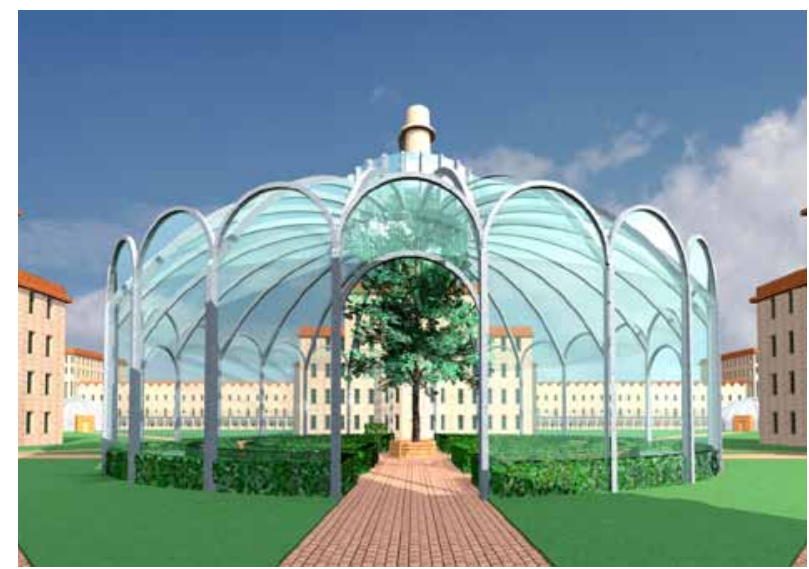

Fig. 6. The central feature of the villages of co-operation - the conservatory of 300 feet in height. The main arteries divided the main square along lines of bilateral symmetry, and all of roads were 100 feet broad. A main feature of Victoria's architecture was the walkways and colonnades (Fig. 7). Each of the domestic rows were fronted with colonnades, and there were covered walkways throughout the city that could be navigated above and below, making communications throughout the town simpler and quicker.

The nineteenth century was rich in plans for the ideal city that would resolve the national crisis of housing. Owen influenced many similar styled villages such as John Minter Morgan's villages of self-sufficiency (Morgan 1849). Morgan's villages were very similar in their architectural structure to Owen's. However, his main point of differentiation was in his political phi-

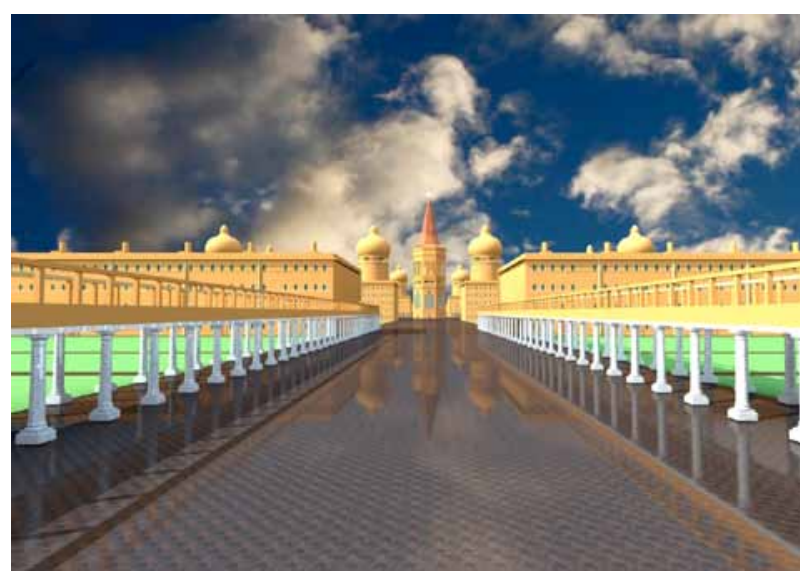

Fig. 7. The walkways of Victoria and looking into the centre 
losophy. Unlike Owen, Morgan integrated Christian principles into the administration and society of the village. Around the same time, other plans for communities became more prevalent such political economist William Thompson's Practical Directions for the Speedy and Economical Establishment of Communities. Thompson envisaged small communities of 2,000 people forming a cooperative nucleus that would be funded by joint stock companies. Like Owen, Thomson believed that a new system of collectivism could be achieved in one district alone and not require the entire country to convert to that particular political agenda (Pankhurst 1954). Thompson defined the method of co-operation as 'the voluntary union of the industrious all productive classes, in such numbers as to afford a market to each other, for the mutual supply, directly by themselves, and all of their indispensable wants (Pankhurst 1954: 378).' However, although Thompson was influenced by Owen's concepts of the community Thompson never planned village or town for his philosophies. Owen and Buckingham's influences were substantial throughout the nineteenth century. Although not all of the villages or towns that were influenced by Owen and Buckingham contained a comprehensive plan, they stimulated a discussion about a comprehensive solution to the national housing crisis that plagued the nineteenth century.

\section{The underlining philosophies of the four cities}

Christianopolis, the City of the Sun, the Villages of Co-operation, and Victoria were never built. They remain as utopian literature, and the architecture was never realised. All four cities represent an attempt to advance the living conditions of the day through enlightened design. They were propagated as solutions to the particular problems of their eras. Despite the span of over 200 years and the differences in the problems they wished to solved, there is a great deal of similarity both in their architecture and in the fundamental principles that underlie the philosophy behind their architecture.

All four cities are 'closed' cities. During the sixteenth century there was a great deal of religious tension that arose from the Protestant Reformation and the creation of new Protestant churches that was instigated by clergyman such as Martin Luther and John Calvin. Through this century, Europe became divided between Protestant and Roman Catholic. The various divisions of both main religions led to continuous fierce conflict and eventually long and violent war (Searle 1974). Andreae's first concern for the town of Christianopolis was its defences. He described the square plan of the town with sides 700 feet long, and it is pretty well defended by for bastions and a rampart. It is very accurately aligned with the four quarters of the earth. Its strength is enforced by eight massive towers distributed throughout Christianopolis, and beyond this there are 16 smaller towers which are not to be despised: and in the middle of oral there is a citadel which is almost impregnable (Andreae 1999: 161-162).

Safety was also a paramount concern in Campanella's City of the Sun. External fortifications consisted of earthworks, guns, towers, ditches and breastworks. The main entrance was shut with an iron gate. The defences and gates were guarded by day and by night. Each of the seven circuits was gated, and there were no ground floor entrances on the external sides of the circuits. Furthermore, it was so built that if the first circle was stormed, then it would require double the effort to storm the second wall; still more to storm the third; and in each successive case the strength and energy would have to be doubled each time. Hence, anyone who wanted to capture that city needed to storm it seven times with an increased effort for each wall (Campanella 1968: 141-142).

Owen and Buckingham were also concerned with safety. However, their concern was not with physical attack, but with attacks by the evils of an industrial society in which people were being replaced by machines and left destitute. The landowners had been in enclosing common land since Elizabethan time and converting it into pasture to raise sheep. However, in the eighteenth century, land enclosures became endemic, and the cottages who were thrown off their land headed towards the cities in search of employment. By the nineteenth century, the housing in cities was a national crisis with overcrowding and ever-growing slums.

Frederick Engels called the migration of the rural labour into British cities 'social murder.' The high density and the decaying urban environment contributed heavily to the cities' mortality and morbidity rates. Yet the towns continued to grow. In 1845, Engels published The Conditions of the Working Class in England in 1844. He claimed that the housing conditions were so poor and expensive that 'no hole is so bad but that some poor creature must take it who can pay for nothing better' (Engels 1952).

Engels described an area in Manchester known as New Town that stretched up a hill of clay. He claimed that at New Town

all the features of a city are lost. Single rows of houses or groups of streets stand, here and there, like little villages on the naked, not even 
grass-grown clay soil; the houses, or rather cottages, are in bad order, never repaired, filthy, with damp, unclean, cellar dwellings; the lanes are neither paved nor supplied with sewers, but harbour numerous colonies of swine in hand in small sties or yards, or wandering unrestrained through the neighbourhood. The mud in the streets is so deep that there is never a chance, except in the driest weather, of walking without sinking into it ankle-deep at every step. In the vicinity of St George's Road, the separate groups of buildings approach each other more closely, ending in a continuation of lanes, blind alleys, and back lanes and courts, which grow more and more crowded and irregular the nearer they approach the heart of the city (Engels 1952: 54-55).

There was a call for change not only by social reformers and politicians but also by the public with the hope of political reform. Even those who were in employment had to take lower wages as well as work longer hours since they were competing against machines. Owen believed that the immediate cause of the national human crisis was the depreciation of human labour. The mechanical improvements continued to stimulate further interventions (Langton 2000; Williamson 2002). The industrial age had increased individual wealth and advanced national prosperity. However, the labouring classes were being exploited and devalued. Owen's Villages of Co-operation would ensure the safety and protection of the individual against the increasing mechanisation and industrialisation of society (see Owen 1817). The initial ideas behind the Villages of Cooperation were to give employment to the unemployed. However, Owen's solution would only work in a close community that had an enlightened governance and an education system that formed the character of the children to advance a more equitable and just society (Owen 1817: 8-9).

Buckingham believed that the right living conditions, including secure and healthy housing, would protect the inhabitants from what he called the 'national evil.' Unlike Owen's villages, Victoria was extremely hierarchical, and he identified ten social classes that are reflected in the different levels of architecture within the city (Buckingham 1849: 211). Nevertheless, within Victoria, each class was safe from the national evil. In Victoria, the central octagonal tower with a spire of 300 feet in height contained an electrical light for illuminating the whole town (Buckingham 1849: 191). Likewise, the plan for the public buildings of the Villages of Co-operation included smoke stacks that were 240 feet high, the stacks doubled as observatories at night, and they also had light towers to ensure that the streets were safe and well lit.

In the City of the Sun, Christianopolis and the Villages of Co-operation, all property was held in common, and there was no private property. Everyone in the community worked for the community. In the City of the Sun and Christianopolis, only the self-sufficiency of the community was considered. In the Villages of Co-operation, after the village achieved sustainability a few years after its construction, goods would be sold outside of the community and profits would be directed to paying for the land that would ensure self-sufficiency. Once that had been achieved, then the profits would be directed to beginning new Villages of Cooperation. Although Buckingham admired the co-operative communities of the Shakers and the Rappites in America, he preached against 'the evils of communism (Buckingham 1849: 10).' He perceived community as a unity for the association of contentment, goodwill and affection. Like Owen, he believed that two of the greatest improvements in the society would be shorter working hours and a larger share of the profits of the labour (Buckingham 1849: 80). Buckingham's Victoria would be a place where people would live in safety, harmony and co-operation. Buckingham believed that his design for Victoria was 'marked by harmony and consistency in all its parts (Buckingham 1849: 10).'

Symmetry also dominated the designs of these four cities. Every road led to somewhere and in particular to the centre. There were no blind or narrow alleys or dead ends. All the roads were broad, and all of the buildings in the four cities had colonnades that made it possible to move round in bad weather. Movement through all of the cities was organized, regulated, convenient and simple. Michael Ostwald claimed that Owen and Buckingham believed that the cities that were constructed of rational symmetrical and geometrical forms could be beneficial to the physical and spiritual wellbeing of its inhabitants. They used geometry as an instrument of enlightened order and control (Ostwald, Moore 1996: 563). The cities of England in the nineteenth century were disharmonious, and Buckingham and Owen's cities presented the complete opposite. The symmetrical urban plans were contained in size, organized and with regulated movements throughout the city.

The symmetry of the plans emphasized social interchange rather than central authority, and they distributed activity throughout the urban space, instead of concentrating it in particular areas. There is a strong sense of order throughout the streets - a contemplative order. There are similarities between Campanella and Andreae's philosophy behind the planning of the City 
of the Sun and Christianopolis as well as the similarity in the moral theology behind the cities. They have similar forms of government and common ownership of property, and they both give prominence to education, especially its orientation to the new sciences. However, there are also significant differences.

Everything in the City of the Sun was related to Campanella's new system of metaphysics which emphasizes the study of nature and scripture. He believed that it is only through the combination of the study of the codes of nature and the divine revelation that it is possible to attain a real synthesis of knowledge (Bonansea 1969: 46-135). Walking from the front gate to the top of the hill and the Temple was to walk through creation according to the images on the wall. Upon reaching the Temple, the visitor was confronted with a domed Temple that was 350 paces in diameter and the dome itself would be approximately 300 paces (408 Feet 124.4 metres) in diameter, which was more than two and a half times the size of Pantheon, the largest dome in the world at the time. In contrast, the human scale of Christianopolis clearly distinguishes itself from the City of the Sun. The domestic buildings, the streets, the workshops and storerooms, and the College were all comparatively modest. The central Temple of building was a large and dominant building and accommodated the entire congregation of 400 . However, with a diameter of 100 feet, its dome was smaller than its contemporary counterparts.

Both the City of the Sun and Christianopolis were monastic communities that were developed for their Christian brotherhoods and included men and women. The mandala, like the plan of the cities, emphasized this monasticism. This concept remained in both Owen and Buckingham's plans, although in different aspects. John Rockey pointed to the connection between Buckingham and Andreae's plans that have features of the City of Revelation. Both cities are uniform, symmetrical in detail, square in outline and focus on a towering spire (Rockey 1981, 1983: 90). This connection is supported by the names of the eight avenues: the Avenue of Unity, Justice, Faith, Hope, Charity, Fortitude, Concord, and Peace. In addition, the number eight, the number of Revelations, prevails in the city, with the main tower being an octagon and there are eight streets and eight rows (Buckingham 1849). Ostwald claimed that this idea of the monastic community was at the heart of Owen's Villages of Co-operation, in his communal ideas and design (Buckingham 1849). These utopian cities were planned with order, and set out with a central ordering principle.

One of the main features of all four cities is the amount of open space. All four cities have over 50 percent of their plan as open space and parks. Patrick Abercrombie pointed out that Buckingham's plan has nearly 180 acres of the 640 acres of the city as roads and another 160 acres of gardens, and this is without counting the central square. This is over three times the planning recommendations of the Housing Commission who preferred a higher density (Abercrombie 1921: 19). Christianopolis' open space is 52 percent of the total plan, and while the Villages of Co-operation does not give exact measurements for the buildings, it is clear from the description of the plan and Whitwell's sketch that the open space is more than 60 percent of the total area. In the City of the Sun, there are large expanses of space in front of the domestic buildings of each circuit. In the first row, the space is 70 paces ( 92.5 feet) and the subsequent rows are three paces less (67 paces; 85.5 feet). Unfortunately, Campanella does not give the width of the housing circuits, but even if they are the same width as the open spaces in front of them, the amount of free space is substantial. The spaciousness of these cities would be surprising today, but in the seventeenth and nineteenth centuries it would have been unprecedented.

The architectural designs of these cities were meant to have aesthetic value; the authors carefully described in detail many of the architectural features, particularly the centralised temples and main buildings. However, the philosophies behind the cities are strongly concerned with the environmental aspects of the city which would enhance their philosophies. All of these four cities offered the citizen order; community; protection; safety; convenience, and amenities. The designs were intended by the authors to promote these aspects, where a community could be enhanced and thrive in a safe and ordered environment. These environmental features remain an attractive feature for any modern urban community.

\section{Evaluating the environmental aspects of the city}

Permeability is a positive attribute of urban design, because it permits the ease of movement through cities and enhances desirable urban aspects such as safety and order. In The Constitution of Society (1984), Anthony Giddens outlined the structuralism of social practices that are inseparable connections of structures and social interaction. Urban space created by the architectural plan is one of the prime means through which society is directly constituted. The spaces that are created by architectural planning integrate society by physically enabling and constraining social interaction. The architectural design arranges social interaction in recurrent patterns that give form to social structure. Giddens' theory of structuration is useful in 
analysing a built environment because it expresses the essential theoretical position in which space that has been defined by architecture does more than present a society - the space assists in the development of the built environment. It goes beyond the buildings into the pattern of the urban space. It is the structure that gives form and shape to social interaction, but it is not the structure alone that gives form or shape.

In The Social Logic of Space (1984), Bill Hillier and Julienne Hanson presented a series of pioneering methods for analysing spatial pattern, known as space syntax (Hillier, Hanson 1984). Space syntax draws connections between spatial configuration and social effects. The formal analysis of spatial arrangements provides information about the structure of society. The prime purpose of the building is the ordering of space. They argue that, 'however much we may prefer to discuss architecture in terms of visual styles, its most far reaching practical effects are not at the level of appearances at all, but at a level of space (i).' The system of space gives shape and form to our material world in which we live in. 'In this sense, architecture pervades our everyday experience far more than a preoccupation with its visual properties would suggest' (Hillier, Hanson 1984).

Justified plan graphs theory (JPG) is a practical analytic method that was developed as a part of space syntax theory and provides a graphical, mathematical analysis of the spatial configuration of cities or buildings. JPG theory makes it possible to not only measure spatial configurations but also to compare cities or buildings. TheJPG theory reduces the plan of the city to a graph of nodes that represents the buildings and connecting lines that represent the paths to the buildings. These graphs simplify the plan of the movement through the cities. So, for example, in the case of the four utopian cities that we have discussed, the multi-stories and the walkways would be included as nodes and connections. ${ }^{1}$

An analysis using JPG theory was carried out by the first author on these four cities with the graphs being prepared according to the walk described below, as a visitor moving from the outside through the city into the centre and returning to the outside (Hanson 1998: 29). The analysis included: the total depth, the sum of the number of connections between a particular node and every other mode in the set; and integration, the relative isolation of the space from each node. The analysis of all four cities revealed that they were highly

\footnotetext{
1 The graph for Victoria consisted of 107 nodes, for the City of the Sun 125 nodes, for Christianopolis 99 nodes and the Villages of Co-operation 56 nodes.
}

integrated systems with the minimum integration at the entrance and the maximum integration in the centre of the city. Although this is not a surprising result given the symmetry of cities that lead to the centre and lack any dead ends, it does confirm the permeability of such an urban plan.

These four cities are all called 'utopian.' In many senses this is used as a derogatory term, because it implies that they are unrealistic, unliveable and have no value in urban design - that their designs were meant for the enhancement of the literature only. As they were never built, their value to urban design and liveability is difficult to assess. To assess the design value of the cities, a survey was undertaken in order to evaluate the architectural and environmental features of these important utopian cities on a modern audience.

\section{The research survey}

Christianopolis, the City of the Sun, the Villages of Co-operation, and Victoria are well known and included in every assessment of utopian cities. However, their design features have never been previously examined, and no prior research has been undertaken to investigate whether people actually perceive these cities to be utopian. In that light, the authors conducted an online survey to evaluate the underlying principles of the literature with the designs of the city. This survey investigated whether the environmental quality and liveability of the city had relevance to a modern audience, and it would also validate the mathematical space syntax assessment.

The participants of the online survey were 148 undergraduate psychology students from an Australian university. Participants were asked to complete the survey in their own time. Participants were asked to view one of the four cities in a two-and-a-half minute slide show that consisted of 25-30 colour slides that were each presented for four seconds.

The cities were modelled using ArchiCAD. Each slide showed a sequential view of the city from the perspective of a person who enters the city, walks around inside it, and then exits the city. The visual representations of the four cities were designed to be similar in terms of their texture, tone, colours, degree of detail, shadows, and daylight (They were all set for at 11.00am in April, Mediterranean location). The study was titled 'virtual walk around a historical city', and it was introduced to participants as 'investigating people's evaluations of a historical city.' These cities had never been modelled before and, consequently, the participants were unfamiliar with the cities

After viewing the walk through the city, participants indicated how much they agreed or disagreed with 
various supplied statements in four areas (1) how positive or negative they felt about the cities (i.e., did they find them pleasant, liveable, enjoyable to walk around); (2) how they perceived the architecture (e.g., spacious, connected, symmetrical); (3) their personal level of individualism and collectivism, (4) demographic variables, including their age, gender, ethnicity, and social class. For example, 'When making decisions, I primarily follow my own needs!' (individualism), 'How easy do you think it is to get from one place to another in the city?' (permeability), 'How symmetrical did you find the architecture?' (symmetry). The participants responded to these items using 7-point scales (i.e., extremely symmetrical to extremely asymmetrical or strongly agree to strongly disagree). They were also asked to describe how they felt about city in one or two words.

As we have reported in greater detail in an article in Journal of General Psychology (Rubin; Morrison 2014), the overall analysis of the survey showed that people who reported a strong sense of self-responsibility (individualism) rated the cities as more liveable because they perceived them to be richer and better resourced. In contrast, people who reported a strong commitment to their social groups (collectivism) rated the cities as having a better environmental quality because they perceived them to provide a greater potential for community and social life. As Rubin and Morrison (2014) explained, individualism and collectivism are cultural orientations towards treating people as individuals or group members respectively (for a review, see Oyserman et al. 2002). Individualists tend to be more independent, autonomous, and self-reliant, whereas collectivists tend to be more interdependent and oriented toward their social groups. The individualismcollectivism distinction is a sociocultural variable, with Western (mainly English-speaking) cultures being regarded as more individualistic and non Western cultures as more collectivistic. Nonetheless, individual differences within each culture are also apparent (e.g., Cross et al. 2000; Kashima et al. 1995; Realo et al. 2002).

Rubin and Morrison focussed on the relation between individualism and collectivisms and the cities' liveability and environmental quality. In contrast, in the present article, we consider how the participants related to design of these cities. In general, participants disliked the architecture. They tended to agree with the statement 'I did not like the architecture of the city.' Their mean score was 3.51 on a 7-point scale (ranging from $1=$ strongly disagree to $7=$ strongly agree), and their score was significantly below the scale midpoint of 4 (neutral), $t(147)=-3.78, p<.001$. The individual word list also revealed a very negative response to the architecture. The majority of the responses were words such as the 'bland,' 'boring,' 'dull,' 'mundane' and 'repetitive.' Only 23 percent of the responses could be classified as positive, but bordering on neutral. With the exception of one response which claimed that the city was an 'architectural delight,' there was a clear disinterest in the architecture. Examples of the positive responses are 'symmetrical and safe,' 'spacious,' 'interesting,' 'uniform and well organized' and 'structured.'

The visual attributes of the architecture clearly did not appeal to the respondents. However, the invisible attributes were much more appreciated. Despite their assessment that the architecture was dull and boring, the spatial patterns created by these utopian cities enhanced feelings of community and permeability. The positive aspects in the survey indicate that the participants were interested in the environmental quality and liveability of the city, particularly safety, order and organisation, spaciousness and permeability or spatial planning. To the questions 'How safe do you think it would be to live in the city?' ( $1=$ extremely unsafe, $7=$ extremely safe) the mean was 5.26 , which was significantly above the scale's neutral midpoint of 4.00 , $t(147)=13.43, p<.001$. Hence, participants perceived the cities to be relatively safe. Participants mean score was 6.16 in response to the question 'How ordered and organized do you find the city?' ( 1 = extremely disordered and disorganised, $7=$ extremely well-ordered and organised). Again, this mean score was significantly above the scale midpoint, $t(147)=26.75, p<.001$, and indicated that participants perceived the cities to be well-ordered and organized. Participants also judged the permeability of the cities to be extremely high, with positive responses that were significantly above the neutral scale midpoints for the questions 'How connected do you feel the buildings are to one another in the city?' ( $1=$ extremely disconnected, $7=$ extremely connected), mean score $=5.47, t(147)=12.15, p<.001$, and 'How easy do you think it is to get from one place to another in the city? $(1=$ extremely difficult, $7=$ extremely easy), , ean score $=5.29, t(147)=10.08, p<$ .001 . Finally, in response to the question 'How much community interaction and social life you think occur in the city?' ( $1=$ none at all, $7=$ a great deal $)$, participants' mean score was 5.39 , which was significantly above the neutral midpoint, $t(147)=10.72, p<.001$. Hence, although the computer representations of the cities contained no people and no signs of life, participants were nonetheless able to imagine the cities as being relatively conducive to social life and community interaction (for more detail on the construction of the survey please see Rubin, Morrison 2014).

The utopian cities' strict structural symmetry gives form to desirable urban features of a liveable city. There 
is a very clear division in the responses to the survey between the physical city and its invisible attributes its spatial patterns

\section{Conclusion}

In these four utopian plans, the city was a vehicle of reform in response to critical historic events. These cities from the seventeenth and the nineteenth century retained the ideal utopian symmetry that stems from Plato. The authors of these cities did not consider the terrain but selected the perfect forms of the square or circle. In the nineteenth century these cities were vigorously discussed as serious solutions to the national urban crisis (Philanthropos 1819; Weston 1817; Pemberton 1855). However, they are now ignored and classified as 'utopian' in the sense that they were never meant to be a built. However, while the philosophies of Campanella, Andreae, Owen and Buckingham have been closely examined, their architecture is rarely given any serious discussion.

These four works are now only considered as utopian literature; however, through their designs these cities have desirable urban features that enhance the community and environment of the city. Their urban environment does appear to address the problems that the authors set out to resolve.

Would these cities be considered utopian or ideal today? The participants of our survey did not know that these cities were thought to be utopian; they only knew that they were historic. One of the questions was 'How perfect and ideal would you rate the city.' The mean response was significantly below the neutral midpoint $(4.00)$ at $3.56, t(147)=-3.88, p<.001$. Hence, the answer from our twenty-first century undergraduate students was that the cities they viewed were not utopian. Nonetheless, the main principles behind the initial design of the city - safety, spaciousness, organized and permeability - were positively appreciated by our participants, and the overall responses to the spatial patterns of the cities were extremely positive. Hence, although the architecture may be unfashionable by today's standards, the intrinsic qualities of the city designs appears to shine through as more durable features, leaving us cities with utopian qualities.

\section{References}

Abercrombie, P. 1921. Ideal cities No 2: Victoria, The Town Planning Review 9: 15-20.

http://dx.doi.org/10.3828/tpr.9.1.t648272017566848

Andreae, J. V. 1614. Fama Fraternitatis Dess Loblichen Orden Des Rosenkreutzes. Strasbourg.

Andreae, J. V. 1615. Confessio Fraternitatis R.C. Strasbourg.
Andreae, J. V. 1999. Christianopolis, in E. H. Thompson (Ed.). Christianopolis. Dordrecht: Kluwer Academic Publishers. http://dx.doi.org/10.1007/978-94-015-9267-3

Armitage, W. H. G. 1958. John Minter Morgan's schemes, 1841 - 1855, International Review of Social History 3: 26-42. http://dx.doi.org/10.1017/S0020859000001036

Bleiler, E. F. 2008. Johann Valentin Andreae, fantasist and utopist, Science Fiction Studies, 35: 1-30.

Bonansea, B. M. 1969. Tommaso Campanella: renaissance pioneer of modern thought. Washington: The Catholic University of America.

Buckingham, J. S. 1849. National evils and practical remedies, with the plan of a model town. London: Peter Jackson, Son, \& Co.

Bythell, D. 1983. Cottage industry and the factory system, History Today 33(4): 17-23.

Campanella, T. 1968. Campanella's City of the Sun, in H. Morley (Ed.). Ideal Commonwealths. Washington: Kennikat Press, 141-179.

Campanella, T. 1968. Campanella's city of the Sun, in H. Morley (Ed.). Ideal Commonwealths. Washington: Kennikat Press.

Carsten, F. L. 1985. Essays in German history. London: Hambledon Press.

Cross, S. E.; Bacon, P. L.; Morris, M. L. 2000. The relationalinterdependent selfconstrual and relationships, Journal of Personality and Social Psychology 78: 791-808. http://dx.doi.org/10.1037/0022-3514.78.4.791

Dixon, D. R. 1998. The Tessera of Antilia: utopian brotherhood and secret societies in the early seventeenth century. Leiden, Boston and Koln: Brill. ISBN: 9789004110328

Engels, F. 1952. The conditions of the working class in England in 1844. London: George Allen and Unwin Ltd.

Giddens, A. 1984. The constitution of society: outline of the theory of structuration. Cambridge: Polity.

Hanson, J. 1998. Decoding homes and houses. Cambridge: Cambridge University Press.

Hillier, B.; Hanson, J. 1984. The social logic of space. Cambridge, New York. http://dx.doi.org/10.1017/CBO9780511597237

Kashima, Y.; Yamaguchi, S.; Kim, U.; Choi, S-. C.; Gelfand, M. J.; Yuki, M. 1995. Culture, gender, and self: A perspective from individualism-collectivism research, Journal of Personality and Social Psychology 69: 925-937.

http://dx.doi.org/10.1037/0022-3514.69.5.925

Langton, J. 2000. Proletarianization in the industrial revolution: regionalism and kinship in the labour markets of the British coal industry from the seventeenth to the nineteenth centuries, Transactions of the Institute of British Geographers 25: 31-49. http://dx.doi.org/10.1111/j.0020-2754.2000.00031.x

Morgan, J. M. 1849. The Christian Commonwealth. London: Phoenix library.

More, T. 2001. Utopia. New Haven and London: Yale University Press.

Ostwald, M. J.; Moore, J. 1996. The science of urban pathology: Victorian rituals of architectural and urban dissection, Australasian Victorian Studies Journal 2: 65-80.

Owen, R. 1817. Report to the Committee of the Association for the relief of the manufacturing and labouring poor. London.

Oyserman, D.; Coon, H. M.; Kemmelmeier, M. 2002. Rethinking individualism and collectivism: Evaluation of theoretical 
assumptions and meta-analyses, Psychological Bulletin 128: 3-72. http://dx.doi.org/10.1037/0033-2909.128.1.3

Pankhurst, R. 1954. William Thompson (1775 - 1833) Britain's pioneer socialist, feminist, and co-operator. London: Watt \& Co.

Pemberton, R. 1855. An address to the bishops and clergy of all the nominations and to all professors and teachers of the Christian world on Robert Owen's proclamation of the millennial state to commence this year (1855). London: Saunders and Oxley.

Philanthropos, J. M. M. 1819. Remarks on the practicability of $\mathrm{Mr}$ Robert Owen's plan to improve the condition of the lower classes. London: Samuel Leight.

Plato. 1955. Republic. London: Methuen.

Plato. 1977. Timaeus and Critias. Harmondsworth: Middlesex Penguin.

Realo, A.; Koiodo, K.; Ceulemans, E.; Allik, J. 2002. Three components of individualism, European Journal of Personality 16: 163-184. http://dx.doi.org/10.1002/per.437

Rockey, J. 1983. From visionary to reality: Victorian ideals cities and model towns in the Genesis of Ebenezer Howard's garden city, The town planning review 54: 83-105. http://dx.doi.org/10.3828/tpr.54.1.k351u944t7429445

Rockey, J. R. 1981. An Australasian utopist, The New Zealand Journal of History 15: 157-178.

Rubin, M.; Morrison, T. 2014. Individual differences in individualism and collectivism predict ratings of virtual cities' liveability and environmental quality, The Journal of General Psychology 141: 348-372. http://dx.doi.org/10.1080/00221309.2014.938721

Searle, G. W. 1974. The Counter Reformation. London: University of London Press.

Weston, J. 1817. Mr. Owen's plan, The Morning Post Thursday, August 29.

Whitwell, S. 1972. Description of an architectural model for a community upon a principal of united interests as advocated by Robert Owen, in K. E. Carpenter (Ed.). Co-operative communities: plans and descriptions. New York: Arno Press.

Williamson, J. G. 2002. Coping with city growth during the British Industrial Revolution. Cambridge: Cambridge University Press.

\section{TESSA MORRISON}

$\mathrm{PhD}$, is a senior lecturer in architectural history at the University of Newcastle, Australia. Her research interests are in philosophy, pure mathematics, historical reconstructions and the history of architecture. Her resent research project is on utopian cities. This project has resulted in the publication of Unbuilt Utopian Cities 1460 to 1900: Reconstructing their Architecture and Political Philosophy published by Ashgate.

\section{MARK RUBIN}

$\mathrm{PhD}$, is a social psychologist at the University of Newcastle, Australia. He is best known for work on social identity and intergroup relations, including research on prejudice and stereotyping. His research interests also include issues related to individualism and collectivism, interdependent problem-solving, migration processes, social class, and social integration. 